\title{
Hereditary predisposition syndromes to malignant hemopathies (HPSMH)
}

\author{
Salomé Dupriez ${ }^{1}$, Xavier Poiré ${ }^{1}$, Hélène Antoine-Poirel ${ }^{1,2} \&$ al

\section{Cliniques universitaires Saint-Luc - UCL, Brussels} \\ '2 Belgian Cancer Registry
}

\section{Introduction}

Inherited predisposition to solid tumors is known to occur in $\sim 5-10 \%$ of new cases. International guidelines are now well established for the genetic counselling and the genetic testing in oncogenetics. In contrast, HPSMH are underdiagnosed and very few recommendations are available.

Owing to the emergence of new sequencing technologies, a hundred of new predisposing genes to hematological malignancies have been identified.

$\rightarrow$ Up to $10 \%$ of malignant myeloid hemopathies may have a genetic predisposition.

$\rightarrow$ HPSMH are difficult to diagnose: incomplete penetrance, heterogenous clinical presentation, sometimes onset in late adulthood, testing with blood or bone marrow will not distinguish between germline and somatic mutations.

$\rightarrow \mathrm{HPSMH}$ are important to identify for the:

- Selection of a suitable follow up program

- Attenuated allograft conditioning in case of Fanconi anemia or telomeropathy

- Selection of an adequate donor without the familial predisposition mutation in case of familial allograft

- Pre-symptomatic diagnosis \& prevention program in relatives

\section{Objectives}

- Retrospective evaluation of HPSMH in a multicentric study in French speaking hospitals

- Proposition of guidelines for the identification and for the follow-up in case of a predisposing mutation

\section{Materials and methods}

Retrospective census.

Selection of Belgian Francophone families or individuals having suffered from several cancers (named as "families"), including at least one malignant hemopathy or aplastic anemia

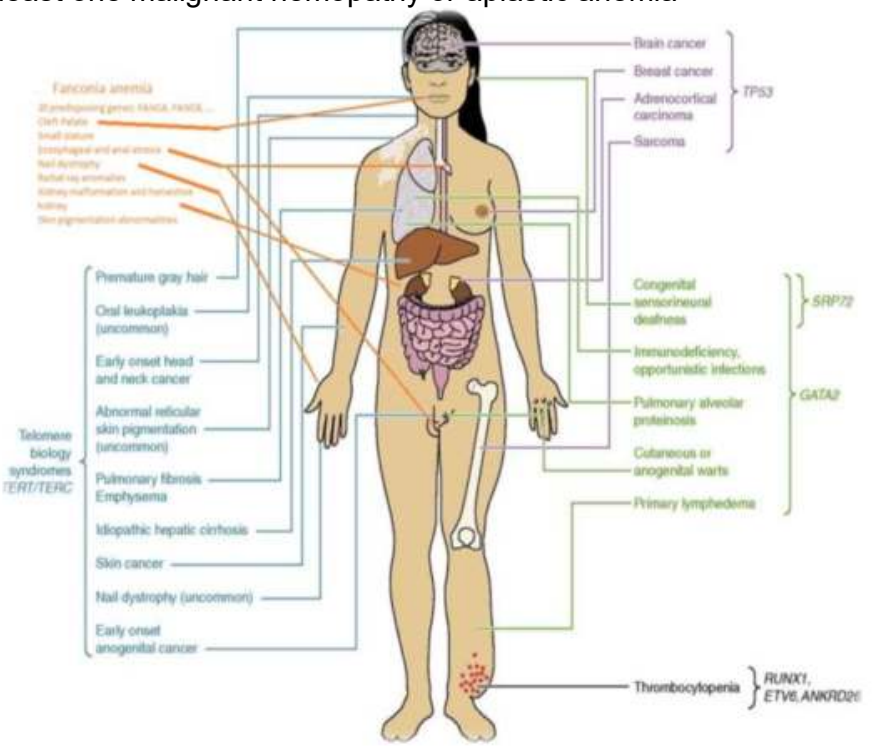

\section{Results}

Information regarding 252 persons belonging to 117 "families" were collected. Predisposing gene mutations in 8 "families" $(6,8 \%)$ were detected:

GATA2 in 2 families: malignant myeloid hemopathies and warts

- Each in 1 "family":

TERT: aplastic anemia + pulmonary fibrosis

FANCA: aplastic anemia + multiple solid cancers in the family TP53: Hodgkin's lymphoma + multiple sarcomas + breast cancers in the family

PTCH1: multiple rhabdomyosarcomas + father with Hodgkin's lymphoma

BRCA1: Hodgkin's lymphoma + breast \& ovarian cancers in the family

ATM: acute lymphoblastic leukemia + gliomatosis cerebri

The retrospective analysis allowed us to suspect a candidate gene in 22 additional "families" (18,8\%): BRCA1/2(18), TP53 (5), ETV6/PAX5(2) (unfortunately, no available material or patients lost of follow-up).

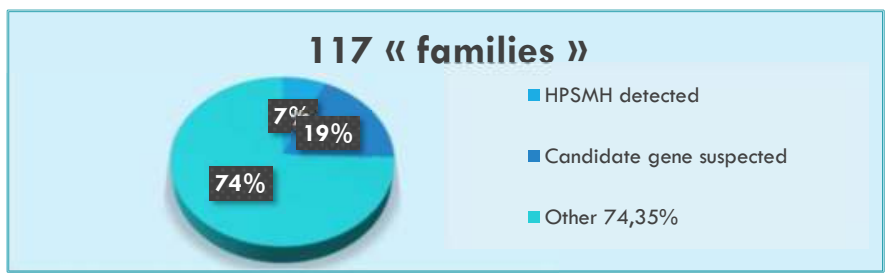

\section{Recommendations}

Based on the literature and our observations:

1.Oncogenetic counselling for patients having suggestive HPSHM features in 3 circumstances:

- familial and/or personal history suggestive of a HPSHM

- potential HPSHM-type germline mutation found in malignant cells

- evaluation of hematopoietic stem cell donors in case of low productive HSC mobilisation.

2.Proposition of genetic tests on candidate genes on uninvaded cells such as fibroblast cell culture, hairs or nails.

3.Specific clinical management and surveillance of patients as well as pre-symptomatic genetic testing for relatives, if an inherited mutation is identified, with a close collaboration between hematology and genetics.

Collaborators:

Augustin Ferrant, Marie-Christiane Vekemans, Bénédicte Brichard, Lucienne Michaux, Thierry Connerotte, Eric Van Den Neste, Christiane Vermylen, Laurent Knoops, Carlos Graux, Francois Duhoux, Catherine Lambert.

Main sources:

- Churpek, J. E., \& Godley, L. A. How I diagnose and manage individuals at risk for inherite myeloid malignancies. Blood 2016 ; 128(14) : 1800-1813.

- Kohlmann W., \& Schiffman J. D. Discussing and managing hematologic germ line variants. Blood $2016 ; 128(21): 2497-2503$.

- Godley L. A., Shimamura A. Genetic predisposition to hematologic malignancies: management and surveillance. Blood 2017; 130(4): 424-432.

- Belgian Cancer Registry, Brussels. 